\title{
Pandemia da Covid-19: Perspectiva Feminina sobre o Isolamento Social
}

Covid-19 Pandemic: The Female Perspective on Social Isolation

Pandemia de Covid-19: Perspectiva Femenina acerca del Aislamiento Social

\author{
Ana Carolina Silveira e Silva Streit \\ Ana Carolina Peixoto Silveira Moraes \\ Carolina Marchese Tirelli Rocha \\ Luiza Demiquei Gonzatti \\ Renata de Farias Paese \\ Vanessa Silva \\ Luciana Suárez Grzybowski ${ }^{1}$ \\ Mariana Gonçalves Boeckel \\ Universidade Federal de Ciências da Saúde de Porto Alegre (UFCSPA)
}

\begin{abstract}
Resumo
O isolamento decorrente do coronavírus (covid-19) trouxe diversas implicações no âmbito familiar, profissional e social, repercutindo intensamente no cotidiano. Assim, este estudo objetivou compreender a perspectiva feminina sobre o isolamento social, decorrente da pandemia da covid-19. O delineamento foi qualitativo, descritivo-exploratório e transversal, realizado com servidoras públicas de uma universidade federal do Sul do Brasil. As informações foram coletadas por questionário sociodemográfico e grupo focal. A partir da análise dos dados, emergiram quatro temáticas: a) (des)adaptação à nova rotina; b) "panela de pressão" dentro de casa; c) individualidade e conjugalidade; e d) estratégias de enfrentamento. Os resultados evidenciaram o agravo de um fenômeno conhecido: a sobrecarga feminina. Foram revelados os desafios da adaptação à nova rotina, as demandas dos diferentes papéis desempenhados pelas mulheres (mãe, trabalhadora, dona de casa, esposa) e o esgotamento emocional diante da expectativa de dar conta de tudo.
\end{abstract}

Palavras-chave: covid-19, isolamento social, esgotamento emocional, papéis da mulher

\begin{abstract}
The isolation resulting from the coronavirus (covid-19) brought several implications to the family, professional and social spheres, with an intense repercussion in daily life. Hence, this study aimed to understand the female perspective on social isolation experienced due to the covid-19 pandemic. The design was qualitative, descriptive exploratory and cross-sectional, carried out with female public workers from a federal university of southern Brazil. The data were collected by sociodemographic questionnaire and focus group, and the analysis pointed to four themes: a) (dis)adaptation to the new routine; b) "pressure cooker" at home; c) individuality and conjugality; and d) coping strategies. The results highlighted the aggravation of a known phenomenon: women's overload. Also, the challenges of adapting to the new routine were revealed, as well as the demands of the different roles played by women (mother, worker, housewife, wife) and the psychological exhaustion from the expectation of taking care of everything.

Keywords: covid-19, social isolation, psychological exhaustion, women's roles
\end{abstract}

\section{Resumen}

El aislamiento resultante del coronavirus (covid-19) trajo varias implicaciones en el ámbito familiar, profesional y social, con una intensa repercusión en la vida cotidiana. Así, este estudio tuvo el objetivo de comprender la perspectiva femenina acerca del aislamiento social, experimentado debido a la pandemia covid-19. El diseño fue cualitativo, descriptivo-exploratorio y transversal, realizado con servidoras públicas de una universidad federal del sur de Brasil. La información se recogió a partir de un cuestionario sociodemográfico y un grupo focal. Del análisis de los datos emergieron cuatro temas: a) (des)adaptación a la nueva rutina; b) "olla a presión" dentro de la casa; c) individualidad y conyugalidad; y d) estrategias de afrontamiento. Los resultados evidenciaron

\footnotetext{
${ }^{1}$ Endereço de contato: Rua Sarmento Leite, 245, Centro Histórico, Porto Alegre, RS. Fone: (51) 3303-8826. E-mail: lucianasg@ufcspa.edu.br
} 
el agravamiento de un fenómeno conocido: la sobrecarga femenina. Se revelaron los desafíos de adaptarse a la nueva rutina, las exigencias de los diferentes roles que desempeñan las mujeres (madre, trabajadora, ama de casa, esposa) y el agotamiento emocional frente a la expectativa de ocuparse de todo.

Palabras clave: covid-19, aislamiento social, agotamiento emocional, papeles de la mujer

\section{Introdução}

A doença causada pelo novo coronavírus, covid-19, emergiu de forma global e repentina em dezembro de 2019, gerando uma pandemia mundial. Acometeu mais de 105,4 milhões de pessoas e, até o início de 2021, mais de 2,3 milhões de mortes já foram reportadas (World Health Organization [WHO], 2021). Sem medicação específica e, até recentemente, sem vacinas, o distanciamento social vem sendo a medida imposta para conter a propagação do vírus. Apesar de necessária e adequada, torna-se importante considerar os efeitos dessa medida no bem-estar da população (Yip \& Chau, 2020).

Além de impactos na saúde física e econômica das pessoas, o novo coronavírus repercute negativamente na saúde mental da população (Brooks et al., 2020). De forma súbita e altamente infecciosa (Wang, Di, Ye, \& Wei, 2020), esta é uma doença que traz altos níveis de ansiedade antecipatória, e o distanciamento social afeta mecanismos básicos de enfrentamento (Horesh \& Brown, 2020). Segundo Qiu et al. (2020), 35\% dos mais de 50 mil participantes de seu estudo apresentaram sofrimento psicológico durante a pandemia da covid-19 na China, sendo maior a prevalência entre mulheres e entre pessoas de 18 e 30 anos ou acima de 60. Da mesma forma, profissionais e pessoas com níveis mais altos de educação tendem a apresentar maiores níveis de sofrimento psicológico e maior risco de depressão (Qiu et al., 2020; Wang et al., 2020).

Neste contexto, a rotina e as relações familiares vêm sofrendo alterações importantes, requerendo adaptações e flexibilidade por parte de seus membros (Cluver et al., 2020). Com as crianças afastadas da escola, dos amigos e das atividades ao ar livre, todas as necessidades destas precisaram ser atendidas em casa, incluindo alimentação, lazer, descanso e, se possível, educação (Alon, Doepke, Olmstead-Rumsey, \& Tertilt, 2020). Somam-se a isso os afazeres domésticos e as demandas profissionais, tanto a distância quanto presencialmente (Coyne et al., 2020). A forma como a família se organizará para atender a todas essas demandas dependerá da flexibilidade no trabalho de cada um dos cônjuges e também da forma como já vinham se organizando em relação aos cuidados da criança, sendo um desafio especialmente difícil para famílias monoparentais (Alon et al., 2020).

Torna-se importante destacar a influência dos papéis de gênero na divisão das tarefas domésticas. De acordo com a Entidade das Nações Unidas para a Igualdade de Gênero e o Empoderamento das Mulheres (Organização das Nações Unidas [ONU], 2020), diante da saturação de sistemas de saúde e do fechamento de escolas, as mulheres se tornaram as mais atingidas pela sobrecarga de trabalho, passando a assumir tarefas de cuidado de familiares doentes, idosos e crianças, assim como tarefas domésticas. A diferença de gênero em relação à parentalidade evidencia-se, ainda mais neste momento, com as mulheres passando aproximadamente duas vezes mais tempo com as crianças do que os homens (Zhou, Hertog, Kolpashnikova, \& Kan, 2020). Diante da nova realidade, há um declínio drástico no bem-estar das mulheres, principalmente das que são mães (Zhou et al., 2020). 
Evidencia-se, portanto, a necessidade do cuidado com a saúde mental da população diante da pandemia da covid-19, tornando investigações sobre suas reverberações na família e no contexto doméstico de suma importância. Este artigo objetiva apresentar percepções de mulheres acerca dos desafios enfrentados no âmbito doméstico durante o isolamento social devido à covid-19.

\section{Método}

\section{Delineamento}

O presente estudo é qualitativo, descritivo-exploratório e transversal, realizado com servidoras públicas de uma Universidade Federal do Sul do Brasil.

\section{Participantes}

Duas mulheres, servidoras de uma Universidade Federal no sul do Brasil, ambas brancas, com 36 anos de idade e técnicas administrativas com nível de escolaridade superior completo. Uma das participantes era casada e tinha dois filhos, um de três e outro de dez anos, com carga horária de 40 horas semanais. A outra participante era separada e tinha um filho de três anos, com o qual coabitava, e tinha carga horária laboral de 20 horas semanais. As duas mulheres estavam em trabalho totalmente remoto.

\section{Instrumentos para coleta das informações}

Foi utilizado um questionário de dados sociodemográficos, laborais e de rotina doméstica (Moraes et al., 2020), com intuito de conhecer características pessoais, do trabalho remoto e dados da rotina familiar.

Além disso, foi realizado um grupo focal conduzido por duas moderadoras por intermédio de questões semiestruturadas e dissertativas que nortearam o encontro, suscitando concepções, percepções, sentimentos e opiniões das participantes diante da interação propiciada (Creswell, 2010). A escolha desta técnica deveu-se ao fato de que, por intermédio dela, os membros do grupo podem explorar seus pontos de vista a partir de reflexões sobre um determinado fenômeno social, gerando suas próprias perguntas e buscando respostas. As perguntas iniciais do encontro estavam relacionadas com a compreensão das motivações para a participação do encontro (o que trouxe você para o grupo?). Após este momento, introduziram-se perguntas atreladas mais especificamente às vivências da pandemia ("como você tem vivenciado a pandemia?"; "Como você se sente diante das inúmeras demandas na pandemia?"; "Quais mudanças você percebe na vida em família?"). Foram realizadas, ainda, questões que buscavam compreender as estratégias de enfrentamento trazidas pelas participantes; exemplo: "Como vocês têm lidado com essa situação?".

\section{Procedimentos de coleta das informações}

O grupo conduzido fez parte de uma iniciativa da universidade para o enfrentamento da pandemia. O convite para participação no encontro sobre a experiência da quarentena foi divulgado para todos os servidores da universidade (técnicos administrativos e professores), 
por meio de e-mail institucional, contendo link para inscrição. Somente duas servidoras se inscreveram neste encontro. Elas foram contatadas pela equipe de pesquisa via e-mail e informadas de que o encontro seria um espaço para compartilhamento de experiências e, também, para pesquisa, sendo apresentados o título e os principais objetivos do projeto.

Esta mensagem de e-mail continha o Termo de Consentimento Livre e Esclarecido (TCLE), o questionário de dados sociodemográficos e o link de acesso para o encontro, via plataforma Zoom, confirmando data e horário previamente divulgados. Ainda que o grupo tenha sido conduzido de forma virtual, a adesão das participantes ao grupo e a condução do grupo mostraram-se bastante satisfatórias. Pequena interferência do ambiente no qual elas estavam ocorreu (e.g., uma das participantes foi requisitada a atender o filho durante o grupo). O encontro foi gravado, conduzido por duas moderadoras, e durou aproximadamente 1h30min.

\section{Procedimentos de Análise das Informações}

A transcrição do grupo focal foi analisada por meio da Análise Temática, um método qualitativo que organiza e descreve o conjunto de dados de forma rica e detalhada (Braun \& Clarke, 2006). Nele, o pesquisador identifica, analisa e relata padrões que surgem ao longo do processo de análise, que podem também ser considerados temas. O processo da Análise Temática envolve seis estágios que não transcorrem de forma linear, mas sim recursiva, e o pesquisador circula entre as fases de acordo com a necessidade (Braun \& Clarke, 2006). Esses estágios envolvem familiarizar-se com os dados; gerar códigos iniciais; buscar temas nos dados coletados; revisar temas; definir e nomear temas; e redigir o relatório (Braun \& Clarke, 2019).

\section{Aspectos Éticos}

A pesquisa foi aprovada pelo Comitê de Ética em Pesquisa da universidade (CAAE 32356520.3.0000.5345) e está de acordo com a Resolução n. 510/2016 do Conselho Nacional de Saúde para pesquisa em Ciências Humanas e Sociais.

\section{Resultados e Discussão}

A partir das respostas ao questionário de dados sociodemográficos, laborais e de rotina doméstica e do relato das participantes, conferiram-se fortes semelhanças entre essas duas mulheres. Ambas são brancas, com nível superior completo e acesso à Internet, o que possibilitou este estudo, haja vista a coleta de informações ter sido virtual. Suas rotinas também eram relativamente semelhantes, mas, enquanto uma era casada (nome fictício Petúnia), tinha dois filhos e uma carga horária de trabalho semanal de 40 horas; a outra era divorciada (nome fictício Magnólia), tinha um filho e uma carga horária de trabalho semanal de 20 horas. Tais diferenças, por vezes, geraram demandas específicas para cada mulher, conforme relatos expressos por elas. Neste sentido, esses relatos possibilitaram a emergência de quatro temáticas principais: (des)adaptação à nova rotina, "panela de pressão" dentro de casa, individualidade e conjugalidade e estratégias de enfrentamento, as quais são descritas a seguir: 
A (des)adaptação à nova rotina foi uma das temáticas mais observáveis na fala das participantes. Tal categoria abrange questões relativas ao excesso e acúmulo de tarefas assumidas pelas mulheres, explicitando dificuldade em conciliar tarefas domésticas, laborais e parentais no contexto privado. Essas situações evidenciaram-se, de forma frequente, em falas das participantes durante o encontro: "Eu não vejo a hora de voltar, eu não aguento mais lavar a louça, lavar roupa, limpar a casa, arrumar a casa" (Magnólia, comunicação pessoal, 5 de junho, 2020). Revelou-se uma sobreposição entre as atividades realizadas e o excesso de tempo compartilhado entre os integrantes da família nuclear. Essa sobreposição levou à falta de privacidade e à falta de tempo para algumas atividades específicas:

... A atividade que tu vai fazer um pouco, às vezes dobra o tempo, porque depende de atenção, e cuidado, e bagunça, e tempo pra limpar; mas eu tô me virando assim, me organizei do meu jeito, com os meus horários. Então a questão que eu tava falando dos horários de trabalhar na noite, de madrugada, que eu tento botar ele (filho) a dormir umas nove, nove e meia, pra poder sobrar mais tempo pra depois poder trabalhar no computador. (Magnólia, comunicação pessoal, 5 de junho, 2020)

$\mathrm{Na}$ fala dessa participante, pode-se perceber que as tarefas ganham destaque e o tempo de descanso acaba sendo usado para mais demanda de trabalho, como apontado na literatura, quando refere que as repercussões da pandemia têm implicações que levam a sofrimento psicológico e a sentimentos de desamparo e abandono, para além do medo do contágio e da doença (Ornell, Schuch, Sordi, \& Kessler, 2020). Observou-se nas participantes a intensa sobrecarga que a doença do novo coronavírus trouxe diante de alterações nas dinâmicas de organização previamente estabelecidas. A transposição do universo profissional para o âmbito privado, o isolamento social e a carência de rede de apoio mostraram-se vetores de grande sofrimento psíquico.

Também, ganhou destaque a ampliação de tarefas relacionadas aos filhos, embora as mulheres ainda expressassem o desejo de dedicarem mais tempo a eles, como demonstrado a seguir:

Eu não faço nada, nada pedagógico com ele [filho], que eu sei que eu deveria estar fazendo, muito em função dessa minha autocobrança com o trabalho, e eu acho que isso é o que tem mais pesado. Porque ontem eu fechei o meu dia e disse, não, o dia de amanhã não pode ser assim, não pode o meu filho pedindo o dia inteiro pra eu brincar com ele, e eu dizer que eu não posso . . . (Petúnia, comunicação pessoal, 5 de junho, 2020)

Em contraste com configurações pré-pandemia, na qual os filhos iam para a escola enquanto os pais trabalhavam, hoje a possibilidade de distanciamento dos filhos é praticamente inexistente, trazendo a sensação de que não existe fim para as demandas das crianças e consumindo tempo e dedicação parentais. Anteriormente, havia uma divisão de funções na rotina, entretanto, nesse cenário de pandemia, para atender às necessidades do filho, é preciso, em vários momentos, pausar as outras atividades e ajustar o horário de trabalho dentro dessa nova configuração:

... a gente não para nunca ... então, é o xixi, é toda hora . . . e ele não vai sozinho, tem que ir junto, tem que trocar a roupa, tirar a cueca, tem que limpar, tem que esperar, porque não quer ficar sozinho no banheiro. Então acaba que não sobra muito tempo; aí 
tu vai na cozinha, vai fazer o almoço, vai lavar a louça, vai secar, vai guardar, quando tu vê. . . já são três e meia. (Magnólia, comunicação pessoal, 5 de junho, 2020)

A sobrecarga decorrente das tarefas domésticas e do cuidado com os filhos mostrou-se intensa, independentemente da configuração conjugal. Ou seja, mesmo a participante que coabitava com o companheiro relatou não poder contar de forma significativa com o apoio e a divisão dessas atividades, justificando que ele trabalhava de forma presencial:

... Porque o meu marido ele me ajuda muito, mas ele trabalha de tarde e de noite; então de manhã que eu tô mais calma com as crianças, ele tá, me ajuda tudo, me ajuda com almoço, quando ele está. Mas isso, realmente, a gente tem que lidar com essa questão, porque parece que a gente tá debaixo de um furacão, assim ... acontece que eu vejo ele pouco. Quando eu vejo ele, que é de manhã a gente tá sempre envolvido com alguma coisa, e às vezes nem conversar a gente conversa, só pelo WhatsApp de noite quando as crianças se acalmam, ele tá trabalhando e eu em casa, aí a gente se fala pelo Whats. (Petúnia, comunicação pessoal, 5 de junho, 2020)

Esses resultados se alinham aos Dados da Pesquisa Nacional por Amostra de Domicílios Contínua (Instituto Brasileiro de Geografia e Estatística [IBGE], 2019), que apontam que normalmente as mulheres já possuem uma rotina muito mais estafante do que a rotina dos homens, no Brasil. Segundo estes dados, as mulheres com ocupação profissional dedicam, em média, oito horas a mais a atividades ligadas a afazeres domésticos e/ou ao cuidado de pessoas, se comparadas a homens com ocupação profissional. Tais aspectos reforçam evidências de que mulheres são mais afetadas pelo aumento das tarefas domésticas no contexto da pandemia (Alon et al., 2020). Os achados deste estudo corroboram essas informações. A participante que era casada evidenciou sentimento intenso de sobrecarga gerado pelo acúmulo e sobreposição de tarefas laborais, domésticas e familiares, as quais manejava em grande parte sozinha, visto que o marido manteve a rotina de trabalho presencial. Ou seja, mesmo que a participante também mantivesse seu trabalho, ela assumia maior responsabilidade do que o marido nas tarefas de casa.

As participantes demonstraram também grande esforço para tentarem se adaptar à rotina e às exigências, de maneira que questões individuais ficaram em segundo plano, resultando em prejuízos como a perda da privacidade. Tal questão é ilustrada pelo seguinte trecho, dito pela participante que era separada, ao comentar sobre os dias em que o filho fica com o pai:

.. Então quando ele vai pra casa do pai dele eu fico em casa pra limpar, pra arrumar. É o dia que eu faxino a casa, que eu troco roupa de cama, coloco toalha, que eu faço tudo ... Então de repente seria o tempo que eu teria pra mim, mas eu não me permito porque tem que arrumar a casa. (Magnólia, comunicação pessoal, 5 de junho, 2020)

Percebe-se nessa fala o anseio em cumprir diversas atividades, para além do seu trabaIho, aumentando a autocobrança e potencializando um sentimento de sobrecarga. Esses aspectos culminam na frustração por não conseguir realizar tudo da forma como imagina ser a ideal ou como gostaria que fosse. De fato, as mulheres brasileiras apresentam maiores taxas de realização de cuidado de pessoas no domicílio do que os homens, sendo que $85,6 \%$ das mulheres são responsáveis por atividades como alimentar, dar banho, dar remédio e colocar para dormir, em contraste com $67,9 \%$ de homens que se envolvem com este tipo de 
tarefa (IBGE, 2019). O papel feminino, associado ao ato de cuidar, é um legado histórico que mulheres e homens ainda não têm conseguido compartilhar igualitariamente. Na amostra deste estudo, ambas as participantes demonstraram estresse e preocupação intensos relacionados ao cuidado dos filhos e da casa. A sobrecarga com os afazeres vivida por mães em tempos de isolamento social contribui ainda mais para aprofundar a desigualdade de gênero (Collins, Landivar, Ruppanner, \& Scarborough, 2020; Medrado et al, 2021).

Acredita-se que a sobreposição de papéis - ser mulher, mãe, dona de casa e trabalhadora - concentrados no mesmo ambiente e realizados de forma simultânea representa um impacto ainda maior em mulheres com filhos em idade pré-escolar (0-7 anos) (Zhou et al., 2020), como no caso das duas participantes da pesquisa. Além disso, Guiginski e Wajnman (2019) referem que mulheres trabalhadoras com filhos pequenos são as que exibem a maior taxa de desemprego no Brasil, devido à maior atenção que crianças desta idade exigem. Diante do cenário de fechamento de escolas em função da pandemia, a sobrecarga se acentua com o acréscimo da demanda de auxílio dos filhos com as aulas on-line. Apesar de estudos salientarem que mães com filhos pré-escolares necessitam reduzir suas cargas horárias quatro a cinco vezes mais que os homens para dar conta destas novas atividades (Collins et al., 2020; Montali, 2012;), as participantes desta pesquisa continuaram com a mesma carga horária de trabalho de antes da pandemia, evidenciando maior desgaste para conseguir cumprir todos os seus afazeres.

O segundo grande tema foi denominado "panela de pressão" dentro de casa, contemplando os sentimentos e as emoções emergentes deste contexto de isolamento. Há incremento da ansiedade e redução drástica dos canais de alívio dela:

A gente se sente, às vezes parece que eu tô debaixo de um turbilhão de coisas que eu não consigo dar conta. ... Mas isso, realmente, a gente tem que lidar com essa questão, porque parece que a gente tá debaixo de um furacão, assim. (Petúnia, comunicação pessoal, 5 de junho, 2020)

As participantes também relataram altos níveis de exigência com as múltiplas tarefas, cobrança excessiva e culpa por não darem conta de tudo, como pode ser visto a seguir em relação ao trabalho:

. . . então chega processo, a gente tem que dar andamento, e as pessoas também não têm muita paciência, então, assim, elas querem tudo pra ontem, e isso nos gera um peso, assim, uma responsabilidade. Claro, tu quer cumprir, tu quer atender, mas ao mesmo tempo a gente tem a questão de lidar com tudo isso, né . . . (Petúnia, comunicação pessoal, 5 de junho, 2020)

E aos filhos:

Porque, eu não consigo fazer com ele; pra mim conseguir trabalhar no computador tem que deixar ele no computador; ai se eu vou trabalhar 2, 3 horas no computador, eu acho muito tempo deixar ele olhando 2, 3 horas um tablet, uma TV, então ... (Magnólia, comunicação pessoal, 5 de junho, 2020)

Notou-se, em ambas as participantes, elevada autoexigência para cumprir todas as tarefas da melhor forma possível, deixando o autocuidado em segundo plano. Assim, o envolvimento e a exigência para dar conta de todas as demandas podem ser vistos como 
alternativas para lidar com o sofrimento diante do contexto adverso; no entanto acabam por gerar um esgotamento ainda maior.

Percebe-se ainda que essa ansiedade excessiva traz sofrimento psíquico, demonstrado por sentimento de tristeza, esgotamento emocional e cansaço extremo, como ilustrado nesta fala:

E isso parece que gera um cansaço mental, né, porque depois do retomar de onde tu parou, de onde eu parei, o que que eu tava fazendo, o que eu preciso fazer, isso cansa a gente mentalmente. Tem dias que realmente, chega final assim da tarde, um peso mental, assim, parece que minha cabeça vai explodir. (Petúnia, comunicação pessoal, 5 de junho, 2020)

Há a sensação de um trabalho inacabável, gerando mais estresse: "E parece que as coisas não têm fim, nada tem fim [risos]" (Magnólia, comunicação pessoal, 5 de junho, 2020). Além da sobrecarga do trabalho em casa, tarefas domésticas e cuidados com os filhos, comentados na temática anterior, uma das participantes ainda relatou se sentir inútil por ter seu trabalho adaptado, de tal forma que perdeu sua identidade principal:

Então tá sendo bem difícil assim [a adaptação do trabalho em casa], porque a gente tá mais na área prática, aí tu passar a trabalhar do computador. . . A gente tá fazendo bem assim, as boas práticas do laboratório no computador. . . Tabela de controle, de registro de temperatura, de manutenção, de uso. Então a gente tá tentando achar coisas pra fazer que possam ser feitas no computador, e não mais prático. Mas vai chegar uma hora, assim, que se isso se prolongar muito, que a gente não vai ter mais o que fazer, só que a gente tem que entregar trabalho ... a gente se sente meio inútil, mas, ao mesmo tempo que se sente meio inútil de não poder ajudar, a gente entende também que não tá podendo não é por, né, não é porque não quer. (Magnólia, comunicação pessoal, 5 de junho, 2020)

O sentimento de culpa por não dar conta das atividades como gostariam é também mencionado em diferentes momentos, como neste trecho: "É uma culpa que ela caminha assim, ela se desmembra pra todos os lados, a culpinha aquela assim; pra todas as áreas!" (Petúnia, comunicação pessoal, 5 de junho, 2020).

Considerando a transposição do ambiente profissional para o ambiente doméstico, observaram-se nas falas das participantes dificuldades no manejo das emoções e na aceitação dos limites na realização das tarefas diárias. Esses achados corroboram com Faro et al. (2020), pois indicam que é esperada, durante uma pandemia, a ocorrência de alterações emocionais significativas, sendo a capacidade de alcançar um nível de ajustamento psicológico saudável um desafio diante das adversidades do período.

Ademais, fica explicitada a frustração ante o desejo de relacionamento social, que é freado pelo medo de contaminação pelo vírus:

Mas o meu medo não é de pegar; o meu medo é ser a transmissora pra alguém, e este alguém passar mal. Então é por isso que a gente fica mais isolado, assim, com medo de tá se relacionando com outras pessoas. (Magnólia, comunicação pessoal, 5 de junho, 2020)

A interação social é uma necessidade básica humana (Sluzki, 1997). Conforme define Sluzki (1997), a rede social pessoal é um dispositivo central na constituição da identidade, 
do pertencimento, da segurança, do bem-estar, do sentir-se competente e agente da própria vida. A rede social pessoal pressupõe relações estabelecidas com a família, as amizades, as relações de trabalho/estudo, relações construídas na comunidade (pessoas, locais, instituições), da qual as participantes se ressentem e sofrem por estarem afastadas neste momento.

O terceiro tema refere-se à individualidade e conjugalidade, refletindo a falta de tempo para si, para o autocuidado e para a relação conjugal. "É, vou te dizer que eu fico, eu acho que eu fico por último, assim, né. Depois todo mundo vai dormir, às vezes as crianças dormem antes que eu, acabou que não sobrou pra mim o dia, mas enfim ... [risos]" (Petúnia, comunicação pessoal, 5 de junho, 2020). A falta de tempo para investir na relação conjugal, quando existente, também foi referida: "Mudou um pouco assim, porque eu vejo que, eu sinto que, e as atividades mudaram, esse excesso de atividades em casa, parece que não sobra tempo, né, acaba ficando por último o pobre coitado ... [risos]" (Petúnia, comunicação pessoal, 5 de junho, 2020).

O envolvimento em múltiplas tarefas faz com que o tempo para si e para o parceiro seja escasso ou inexistente, trazendo um potencial para estresse e sobrecarga maior ainda. "Às vezes chega, né, ontem era uma e meia da manhã, eu digo 'desisti'. Deita aqui, vamos dormir, [risos] não vou conseguir ver nada, não vou conseguir ..." (Petúnia, comunicação pessoal, 5 de junho, 2020). Em um contexto adverso, no qual a separação entre o mundo privado, profissional, de lazer e público restringiram-se ao doméstico, ao mesmo tempo em que há uma importante restrição da rede de apoio externa à família, o investimento em si e na relação conjugal ficam intensamente limitados, transformando-se em mais um fator de sobrecarga e desgaste.

Parece importante considerar o efeito da configuração familiar no enfrentamento da realidade atual, especialmente na sobrecarga feminina. Ter um companheiro coabitando não significa a igualdade na divisão das tarefas, como já bem apontado na literatura. Mesmo a participante que era casada relatou ter pouco apoio conjugal na divisão das tarefas domésticas, revelando que a conjugalidade, a qual poderia ser fonte de apoio mútuo, tornou-se uma demanda entre tantas outras. Obviamente, além da situação conjugal, aspectos como qualidade da relação, tipo de trabalho e tempo de ocupação do companheiro, disponibilidade e apoio seriam importantes variáveis a considerar.

Por fim, as estratégias de enfrentamento também se mostraram significativas no relato das participantes, compondo a quarta temática. Considerando os custos psicológicos, ressalta-se a importância do desenvolvimento de estratégias de enfrentamento que facilitem o processo transacional que um momento de crise como esse impõe (Barros-Delben et al., 2020). O confinamento imposto pela pandemia resultou em grandes mudanças na vida da população, restringindo o contato físico e social. Tais mudanças podem estar associadas a dificuldades na readaptação das rotinas e ao adoecimento psíquico (Barros-Delben et al., 2020), sendo fundamental lançar mão de estratégias para lidar com a situação adversa.

Nesse sentido, observou-se nas falas das participantes o uso de negação e do humor para assuntos difíceis, principalmente, por intermédio do tom de voz e risadas, evidenciando a discrepância entre o relato e a forma de comunicá-lo:

E também o fato de, de repente eu até conseguiria me organizar pra ter um tempo e tudo, né. Só que também tá tudo ... Dá insegurança, assim, de tu sair . . Ah, sei lá, é 
complicado assim... Se correr, o bicho pega, e se ficar, o bicho come [risos]. (Magnólia, comunicação pessoal, 5 de junho, 2020)

Além disso, alterar a rotina de trabalho e flexibilizar tarefas foram tentativas relatadas para lidar com a situação:

Então, assim, tudo que tu vai fazer. . Tenta fazer alguma coisa pra facilitar e agilizar a tua vida. Não, não é simples assim. Eu botei ele a desenhar aqui hoje de manhã, porque eu liguei o computador, eu queria ver algumas coisas, e-mail, assim. Aíforrei a mesa, e dei umas tintas com cola pra ele... Aí ele já virou a tinta, pingou na cadeira... Tudo que tu tenta, não, eu vou entreter ele com alguma coisa pra eu também poder fazer alguma coisa. (Magnólia, comunicação pessoal, 5 de junho, 2020)

Associadas às tentativas, muitas vezes frustradas, de readaptação de rotina, as participantes discorreram sobre dificuldades em aceitar limites e imperfeições, comparando-se com outras pessoas que aparentemente dão conta de realizar todas as tarefas, conforme ilustrado na fala a seguir:

... tu olha pros outros, como é que eles dão conta, de arrumar tudo, né, limpar a casa, fazer atividade com, daí eu fico pensando assim, alguma coisa não tá bem, alguma coisa tá errada; não pode ser eu. (Magnólia, comunicação pessoal, 5 de junho, 2020)

Além disso, há certa inflexibilidade em se permitir sentir-se frágil e no acesso às emoções: "Às vezes eu paro pra pensar e aí eu digo, eu não posso parar pra pensar, porque se não, né ... A gente [ininteligível] triste, pra baixo com tudo que tá por vir ainda, né, que nem veio" (Magnólia, comunicação pessoal, 5 de junho, 2020).

Na busca por amenizar o estresse decorrente das alterações de rotina, foi identificada, nas falas das participantes, a busca por distrações e pequenos prazeres cotidianos: "Mas aí eu valorizo muito o banho; o banho é o meu momento de água caindo, aquilo ... " (Petúnia, comunicação pessoal, 5 de junho, 2020), "A rotina que eu não abro mão é do meu chimarrão, então lá pelas sete, eu faço meu chimarrão e sento no sofá" (Magnólia, comunicação pessoal, 5 de junho, 2020), " . . mas aí o chimarrão pra mim é sinal de liberdade do trabalho [risos]. Assim, começa o trabalho da casa, enfim. Mas é, é um ritual, digamos assim" (Petúnia, comunicação pessoal, 5 de junho, 2020). Da mesma forma, uma das participante refere:

Aí, faz mais ou menos umas 3 semanas, há muito tempo atrás eu tinha começado yoga.

Aí eu decidi retomar a yoga em casa, meditar um pouquinho, aí isso tá me ajudando a lidar com tudo isso... Mas, mesmo me ajudando, não é sempre que eu faço, aí a gente fica naquela .... (Petúnia, comunicação pessoal, 5 de junho, 2020)

Uma das principais mudanças geradas pela pandemia foi o rompimento do contato físico e social. Tal mudança, além da sobrecarga emocional, gerou readaptações na logística de divisão de tarefas entre membros familiares, como exemplificado na fala de uma participante:

... Os meus pais tão em pânico, eles não querem ver ninguém, não recebem ninguém. Eles moram pertinho de mim, mas a gente não se vê desde o dia 17 de março, e eles estão realmente em pânico, assim ... Se abalaram muito. Então não vejo eles; então, assim, eles eram uma ajuda que eu tinha, que eu contava, mas agora não tenho mais. (Petúnia, comunicação pessoal, 5 de junho, 2020) 
No discurso das participantes, evidenciou-se o quanto o afastamento de pessoas próximas, sejam familiares, sejam amigos, repercutiu negativamente na saúde mental. Brooks et al. (2020) destacam o rompimento do contato físico e a restrição de liberdade como um dos principais desafios decorrentes do isolamento social e geradores de efeitos psicológicos negativos. Como referido por Wenham, Smith e Morgan (2020), houve uma redução da rede de apoio presencial em decorrência da pandemia. Corroborando tais apontamentos, as participantes relataram que antes era frequente contar com o apoio informal da família extensa nos cuidados com os filhos, tendo agora que dar conta sozinhas. Foi ainda observado o quanto o rompimento dessa rede de apoio presencial modificou a logística familiar, exigindo flexibilidade e criatividade na organização das tarefas.

Neste sentido, a estratégia de enfrentamento utilizada pelas participantes, diante da ruptura do apoio presencial, foi a manutenção da rede de apoio por meio virtual, ainda que de forma frágil: "Até a gente tem algumas reuniões ... e é vídeo . . . Mas o pessoal realmente faz essa reunião só pra desabafar, então isso é bacana, isso ajuda, parece, assim, que fica mais leve" (Petúnia, comunicação pessoal, 5 de junho, 2020), "É os grupos de WhatsApp mais assim, né, de amigas assim, que a gente divide e conversa sobre isso, assim. Mas não tem muito ..." (Magnólia, comunicação pessoal, 5 de junho, 2020). Esta estratégia foi usada como uma alternativa para a manutenção dos relacionamentos interpessoais durante a pandemia e vem sendo apontada como o principal mecanismo para a diminuição da sensação de solidão, pânico e estresse da população (Brooks et al., 2020). Assim, fica evidenciada a importância de manter momentos de prazer para lidar com as adversidades do período de isolamento, bem como a importância do compartilhamento de angústias e desafios do momento com pessoas significativas do ciclo social.

\section{Considerações Finais}

O olhar científico para a esfera privada do lar, durante a pandemia da covid-19, evidencia o agravo de um tema que há muito tempo já é desvelado: a sobrecarga da mulher, mãe, trabaIhadora, dona de casa. As temáticas que aqui emergiram revelam os desafios na adaptação a uma nova rotina de forma abrupta e inesperada, o quanto isso trouxe tensão para dentro de casa e a falta de tempo e o desequilíbrio entre as demandas individuais, conjugais e parentais, assim como a necessidade de buscar estratégias de enfrentamento para lidar com essa situação tão adversa. Nesse processo, evidenciam-se intenso sofrimento, sobrecarga e estresse.

Mais do que nunca foi explicitada a necessidade relacional do ser humano. Durante o isolamento decorrente da covid-19, o apoio emocional e apoio formal para gerenciar a própria vida e a vida familiar (auxílio no cuidado dos filhos, da casa, entre outros) ficaram intensamente restritos, evidenciando a importância das relações, o quanto somos dependentes uns dos outros para administrar a vida. Ainda que a tecnologia viabilize alguma forma de aproximação, não consegue dar conta da complexidade relacional humana.

O estudo limitou-se a um universo pequeno de participantes mulheres de um mesmo contexto laboral e socioeconômico. Tem-se como hipótese que a sobrecarga de trabalho on-line no contexto da pandemia possa ter dificultado que um maior número de pessoas pudesse participar do encontro. É, também, significativo apontar que, como o encontro foi organizado pela própria universidade, os profissionais podem ter se sentido receosos em expor 
questões de suas vidas pessoais. Ainda que o convite tenha sido aberto a todos os servidores da universidade, apenas mulheres participaram, restringindo o acesso ao discurso masculino nesses tempos. Da mesma forma, não houve a possibilidade de escuta de outros membros da família, que certamente contribuem para a dinâmica doméstica neste momento. Assim, sugerem-se estudos com público ampliado, contemplando as lacunas aqui descritas.

Um provérbio africano diz: "É preciso uma aldeia para se educar uma criança", podemos ampliar para "É preciso uma aldeia para gerenciar a vida". Igualdade de gênero, busca por igualdade entre homens e mulheres, a importância das redes relacionais face a face são algumas das importantes evidências deste estudo. Investigações e intervenções com esses objetivos mostram-se de suma importância para uma sociedade com maior potência em vínculos de saúde.

\section{Referências}

Alon, T., Doepke, M., Olmstead-Rumsey, J., \& Tertilt, M. (2020). The Impact of covid-19 on Gender Equality (NBER Working Paper Series, 26947). United States of America: The National Bureau of Economic Research. doi:https://www.doi.org/10.3386/w26947

Barros-Delben, P., Cruz, R. M., Trevisan, K. R. R., Gai, M. J. P., Carvalho, R. V. C., Carlotto, P. A. C., . . . Malloy-Diniz, L. F. (2020). Saúde Mental em Situação de Emergência: Covid-19. Revista Debates em Psiquiatria, 10(2), 18-28. doi:https://www.doi.org/ 10.25118/2236-918X-10-2-3

Braun, V. \& Clarke, V. (2006). Using thematic analysis in psychology. Qualitative Research in Psychology, 3(2), 77-101. doi:https://www.doi.org/10.1191/1478088706qp063oa

Braun, V., \& Clarke, V. (2019). Reflecting on reflexive thematic analysis. Qualitative Research in Sport, Exercise and Health, 11(4), 589-597. doi:https://www.doi. org/10.1080/2159676X.2019.1628806

Brooks, S. K., Webster, R. K., Smith, L. E., Woodland, L., Wessely, S., Greenberg, N. \& Rubin, G. J. (2020). The psychological impact of quarantine and how to reduce it: Rapid review of the evidence. The Lancet, 395(10227), 912-920. doi:https://www.doi.org/10.1016/ S0140-6736(20)30460-8

Cluver, L., Lachman, J. M., Sherr, L., Wessels, I., Krug, E., Rakotomalala, S., . . McDonald, K. (2020). Parenting in a time of Covid-19. The Lancet, 395(10231). doi:https://www.doi. org/10.1016/S0140-6736(20)30736-4

Collins, C., Landivar, L. C., Ruppanner, L., \& Scarborough, W. J. (2020). Covid-19 and the gender gap in work hours. Gender Work \& Organization, 28(S1), 549-560. doi:https:// www.doi.org/10.1111/gwao.12506

Coyne, L. W., Gould, E. R., Grimaldi, M., Wilson, K. G., Baffuto, G., \& Biglan, A. (2020). First things first: Parent psychological flexibility and self-compassion during Covid-19. Behavior Analysis in Practice, 1-7. doi:https://www.doi.org/10.1007/s40617-020-00435-w

Creswell, J. W. (2010). Projeto de pesquisa: Métodos qualitativo, quantitativo e misto (3a ed.). Porto Alegre: Artmed.

Faro, A., Bahiano, M. A., Nakano, T. C., Reis, C., Silva, B. F. P. \& Vitti, L. S. (2020). Covid-19 e saúde mental: A emergência do cuidado. Estudos de Psicologia, 37, e200074. doi:https:// www.doi.org/10.1590/1982-0275202037e200074 
Guiginski, J., \& Wajnman, S. (2019). A penalidade pela maternidade: Participação e qualidade da inserção no mercado de trabalho das mulheres com filhos. Revista Brasileira de Estudos de População, 36, 1-26. doi:https://www.doi.org/10.20947/s0102-3098a0090

Horesh, D., \& Brown, A. D. (2020). Traumatic stress in the age of Covid-19: A call to close critical gaps and adapt to new realities. Psychological Trauma: Theory, Research, Practice, and Policy, 12(4), 331-335. doi:https://www.doi.org/ 10.1037/tra0000592

Instituto Brasileiro de Geografia e Estatística. (2019). PNDA Contínua: Pesquisa Nacional por Amostra de Domicílios Contínua. Recuperado de https://www.ibge.gov.br/estatisticas/ sociais/trabalho/9171-pesquisa-nacional-por-amostra-de-domicilios-continua-mensal. html?=\&t=o-que-e

Medrado, B., Lyra, J., Nascimento, M., Beiras, A., Corrêa, A. C. P., Alvarenga, E. C., Lima, M. L. C. (2021). Homens e masculinidades e o novo coronavírus: Compartilhando questões de gênero na primeira fase da pandemia. Ciência \& Saúde Coletiva, 26(1), 179-183. doi:https://www.doi.org/10.1590/1413-81232020261.35122020

Montali, L. (2012). Desigualdades de gênero no mercado de trabalho e as políticas sociais. Anais do XVIII Encontro Nacional de Estudos Populacionais, Águas de Lindóia, São Paulo, SP, Brasil. Recuperado de http://www.abep.org.br/publicacoes/index.php/anais/article/ view/1901/1859

Moraes, A. C. P. S., Tirelli-Rocha, C. M., Streit, A. C. S. S., Silva, V., Boeckel, M. G. \& Grzybowski, L. S. (2020). Questionário de dados sociodemográficos, laborais e de rotina doméstica. Projeto de Pesquisa "Vivências familiares em período de isolamento social devido ao Covid-19: A experiência de servidores públicos de uma Universidade Federal do Sul do Brasil". Porto Alegre: UFCSPA.

Organização das Nações Unidas. (2020). Gênero e Covid-19 na América Latina e no Caribe: Dimensões de Gênero na Resposta. Brasília: ONU Mulheres Brasil. Recuperado de http:// www.onumulheres.org.br/wp-content/uploads/2020/03/ONU-MULHERES-Covid19_LAC. pdf

Ornell, F., Schuch, J. B., Sordi, A. O., \& Kessler, F. H. P. (2020). "Pandemic fear" and Covid-19: Mental health burden and strategies. Brazilian Journal of Psychiatry, 42(3), 232-235. doi:https://www.doi.org/10.1590/1516-4446-2020-0008

Qiu, J., Shen, B., Zhao, M., Wang, Z., Xie, B. \& Xu, Y. (2020) A nationwide survey of psychological distress among Chinese people in the Covid-19 epidemic: Implications and policy recommendations. General Psychiatry, 33(2), 1-2. doi:https://www.doi.org/10.1136/ gpsych-2020-100213

Sluzki, C. E. (1997). A rede social na prática sistêmica: Alternativas terapêuticas. São Paulo: Casa do Psicólogo.

Wang, Y., Di, Y., Ye, J., \& Wei, W. (2020). Study on the public psychological states and its related factors during the outbreak of coronavirus disease 2019 (Covid-19) in some regions of China. Psychology, Health \& Medicine, 26(1), 13-22. doi:https://www.doi.org/10.1080/13 548506.2020.1746817

Wenham, C., Smith, J., \& Morgan, R. (2020). Covid-19: The gendered impacts of the outbreak. The Lancet, 395(10227), 846-848. doi:https://www.doi.org/10.1016/ s0140-6736(20)30526-2 
World Health Organization. (2021). Coronavirus disease (Covid-19) (Weekly Epidemiological Update). Genebra: WHO. Recuperado de https://www.who.int/publications/m/item/ weekly-epidemiological-update---9-february-2021

Yip, P. S. F. \& Chau, P. H. (2020). Physical Distancing and Emotional Closeness Amidst Covid-19. Crisis, 41(3), 153-155. doi:https://www.doi.org/10.1027/0227-5910/a000710

Zhou, M., Hertog, E., Kolpashnikova, K., \& Kan, M. Y. (2020). Gender inequalities: Changes in income, time use and well-being before and during the UK Covid-19 lockdown. doi:https:// www.doi.org/10.31235/osf.io/u8ytc

Recebido em: 14/10/2020

Última revisão: 10/02/2021

Aceite final: 17/03/2021

\section{Sobre as autoras:}

Ana Carolina Silveira e Silva Streit: Mestranda em Psicologia e Saúde na Universidade Federal de Ciências da Saúde de Porto Alegre (UFCSPA). Psicóloga pelas Faculdades Integradas de Taquara (FACCAT). Formação em Terapia do Esquema pela Wainer Psicologia Cognitiva. E-mail: anacstreit@gmail.com, Orcid: https://orcid.org/0000-0001-6519-0878

Ana Carolina Peixoto Silveira Moraes: Mestranda em Psicologia e Saúde na Universidade Federal de Ciências da Saúde de Porto Alegre (UFCSPA), Bolsista CAPES. Especialista em Terapia Sistêmica com indivíduos, casais e famílias (CEFI). Psicóloga pela Pontifícia Universidade Católica do Rio Grande do Sul (PUCRS). E-mail: anacarolpsmoraes@gmail.com, Orcid: https://orcid.org/0000-0002-8337-5259

Carolina Marchese Tirelli Rocha: Mestranda em Psicologia e Saúde na Universidade Federal de Ciências da Saúde de Porto Alegre (UFCSPA). Psicóloga pelo Centro Universitário Cenecista de Osório (UNICNECRS). E-mail: carolinatirelli@outlook.com, Orcid: https://orcid.org/0000-0002-8608-1184

Luiza Demiquei Gonzatti: Graduanda em Psicologia na Universidade Federal de Ciências da Saúde de Porto Alegre (UFCSPA), bolsista de iniciação científica na UFCSPA. E-mail: luizagonzatti@gmail.com, Orcid: https://orcid.org/0000-0003-4704-9162

Renata de Farias Paese: Graduanda em Psicologia na Universidade Federal de Ciências da Saúde de Porto Alegre (UFCSPA). E-mail: renatapaese@gmail.com, Orcid: https://orcid.org/0000-0002-5550-8632

Vanessa Silva: Mestranda em Psicologia e Saúde na Universidade Federal de Ciências da Saúde de Porto Alegre (UFCSPA). Psicóloga pela UFCSPA. E-mail: hist.va@gmail.com, Orcid: https://orcid. org/0000-0002-1546-7581

Luciana Suárez Grzybowski: Doutora em Psicologia pela Pontifícia Universidade Católica do Rio Grande do Sul (PUCRS). Atualmente, é professora associada do departamento de Psicologia e do programa de pós-graduação em Psicologia e Saúde na Universidade Federal de Ciências da Saúde de Porto Alegre (UFCSPA). E-mail: lucianasg@ufcspa.edu.br, Orcid: https://orcid.org/0000-0002-8471-2421

Mariana Gonçalves Boeckel:. Doutora em Psicologia pela Pontifícia Universidade Católica do Rio Grande do Sul (PUCRS). Atualmente, é professora adjunta do departamento de Psicologia e do programa de pós-graduação em Psicologia e Saúde na Universidade Federal de Ciências da Saúde de Porto Alegre (UFCSPA). E-mail: marianagb@ufcspa.edu.br, Orcid: https://orcid.org/0000-0002-2806-0238 